\title{
A Study on Customer Satisfaction in Mobile Telecommunication Market by Using SEM and System Dynamic Method
}

\author{
Yuanquan Li, Jiayin Qi and Huaying Shu \\ School of Economics \& Management, Beijing University of Posts \& Telecommunications, \\ Beijing 100876, P.R. China Leo8410@gmail.com ssfajy@263.net shuhy@bupt.edu.cn
}

\begin{abstract}
In this article, a new method is presented to research the mechanism of Customer Satisfaction (CS). Firstly, the research model of CS based on the TAM and ACSI is built. Secondly, some important correlation coefficients of research model can be got from the SEM method. Thirdly, with these correlation coefficients, the main functions of system dynamic model are built, and the evolution of the system is simluated with the help of VENSIM. At last, one simple example is designed by using the method and some meaningful conclusions are provided.
\end{abstract}

Keywords: Customer satisfaction, TAM, ACSI, SEM, Telecommunication market

\section{INTRODUCTION}

With the further development of market economy in China and breaking of the telecom industry monopolization, competitions between telecom operators become more and more intense. In order to enhance the ability of competition and sustainable development, customer satisfaction and customer service were mentioned a lot in the telecom operating management recently, even in some companies, customer satisfaction has been set to be an important KPI. But really can enhanced customer service and customer satisfaction improve company's performance?

Prior studies show that, there are positive significant relationship between customer satisfaction and company's financial performance [1, 2], In an important empirical study of this research problem, Anderson, Fornell and Lehmann analyze the relation between CS and financial performance on data obtained from the Swedish Customer Satisfaction Index, after statistic analyzing, they find that "firms that actually achieve high customer satisfaction also enjoy superior economic returns."' [3]

However, the understanding of the constructs that mediate the link between CS and firm profitability is still limited [4]. Recent researches indicate the mechanism of this positive relation is generated from CS to Customer Loyalty, and then to Profitability. The studies that exist find that higher levels of CS lead to greater customer loyalty [5, $1,2]$, which in turn has a positive impact on profitability [1]. Other researchers think it's because the word of mouth effect, they find that satisfied customers can increase profitability by providing new referrals through positive word of mouth [6].

Please use the following format when citing this chapter:

Li, Y., Qi, J., Shu, H., 2007, in IFIP International Federation for Information Processing, Volume 255, Research and Practical Issues of Enterprise Information Systems II Volume 2, eds. L. Xu, Tjoa A., Chaudhry S. (Boston: Springer), pp. 1221-1226. 
In this paper, we try to build an extended customer satisfaction model, and get the correlation coefficient of relationships between variables through method of SEM. And further more, depending on these correlation coefficients, we simulate the dynamic system constructed by customer feel (for example: Customer Satisfaction) and factors related to company performance and stimulate the system evolution process and stable states by adjusting the value of external variable.

\section{THEORETICAL FRAMEWORK}

\subsection{ACSI}

ACSI (American Customer Satisfaction Index) indicates that Customer Expectation, Perceived Quality and Perceived Value influence the CS (Customer Satisfaction), and they are the antecedent variables of CS. Factors in the model of ACSI have causality relationship with each other, through analyzing, we can not only get the Customer Satisfaction of previous consuming experiences, but can also evaluate customer buying attitude and predict long management performance of company.

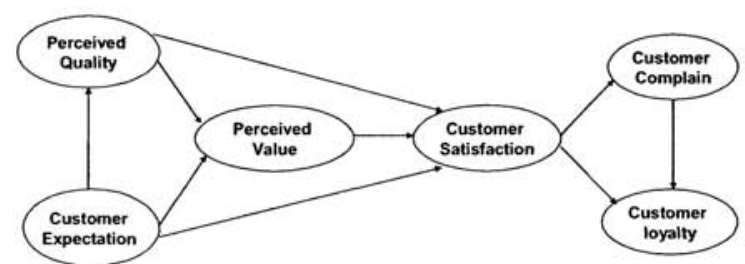

Figure 1. American Customer Satisfaction Index

\subsection{TAM and TRA}

TAM (Technology Acceptance Model) was proposed by Davis in 1989 [8], the purpose of this model is explaining the user adoption of IS technology through user perception. TAM was based the TRA (Theory of Reasoned Action) proposed by Ajzen and Fishbein in 1975 [7]. There are two main variables in TAM, which are PEOU (Perceived Ease Of Use) and PU (Perceived Usefulness), and further more, it notes that External Variables can influence Intention To Use through these two variables.

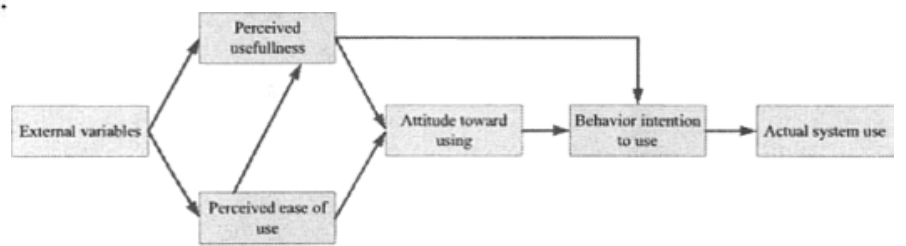

Figure 2. Classical Structure of TAM [7] 
A Study on Customer Satisfaction in Mobile Telecommunication Market by Using SEM and System Dynamic Method 1223

\subsection{Research Model}

Based on ACSI and TAM, we build the model as below:

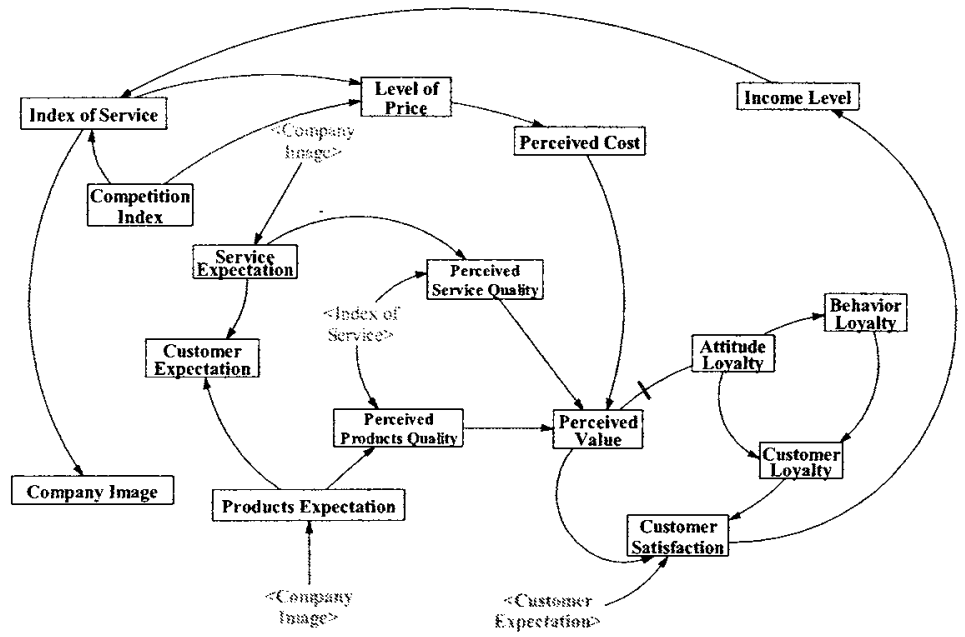

Figure 3. Research Model

\section{ARCHETYPE MODEL ANALYZING}

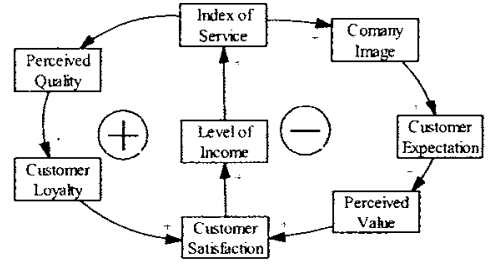

Figure 4. Loop 1

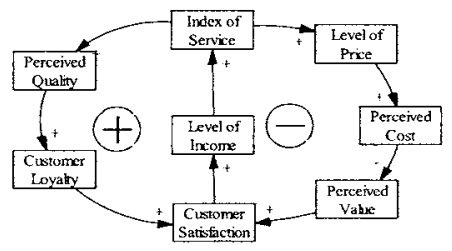

Figure 5. Loop 2

From figures above, we can conclude that, this system is a "limits to growth" system. The growth of the CS can improve the income and Service Quality, and further lift the Perceived Quality and Customer Loyal, and finally enhance the growth of $\mathrm{CS}$; but at the same time, following the improvement of Company Image, Customer Expectation also grows up which lead the decrease of Perceived Value and finally make the decline of CS. In this circle, Customer Expectation is the bottle-neck of CS increase. 
With the development of Service Quality, Price Index is also improved which lift the Perceived Cost and make the Perceived Value decline, and finally lead the decrease of CS. In this circle, Perceived Cost is the bottle-neck of CS increase.

\section{SIMPLE RESEARCH EXAMPLE}

The subjects of this example are students of BUPT (Beijing Univ. of Post and Telecommunication), they are all the subscribers of the same operator. 65 questionnaires are delivered with 60 returned, the response rate is $92.3 \%$. Among these responders, $15 \%$ are undergraduates, $78.33 \%$ are graduates and 3.33 are $\mathrm{Ph} . \mathrm{D}$. graduates. $43 \%$ of the respondents are male and $57 \%$ are female. Average expenditure of total communication per month is 70 Yuan, among these $23.33 \%$ are below 50 , $43.1 \%$ are between $50-100$ and $33.76 \%$ are above 100 .

The data source is got from questionnaires with the variables observed on a 5-point Likert scale. The questionnaire is designed following the TAM and ACSI which are delivered online and the data is gathered in the ACCESS database.

We use SPSS to clear up the raw data (dealing with the outlier and missing values). Then, we use the data to run the SEM model by using LISREL and get the correlation coefficient of variables. Finally, depending on the correlation coefficient, we establish main functions of system dynamic model, the stimulate tool is VENSIM.

\section{RESULTS AND DISCUSSION}

\subsection{Stimulation Results and Discussion}

Assuming that the company's purpose is highest company image and income, the figures below are curves of CS, Company Image and Income Level in three different completion contexts (the intensity levels are 0.8 blue, 1.5 red and 2 green).

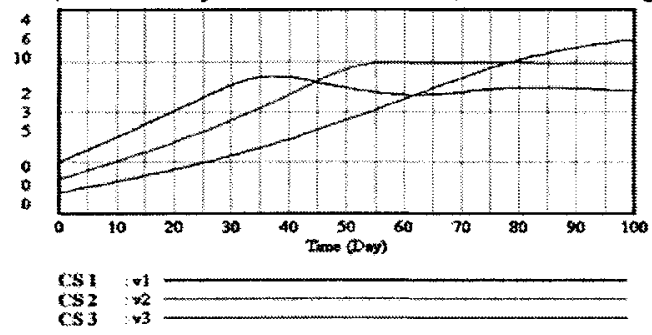

Figure 6. Customer Satisfaction 

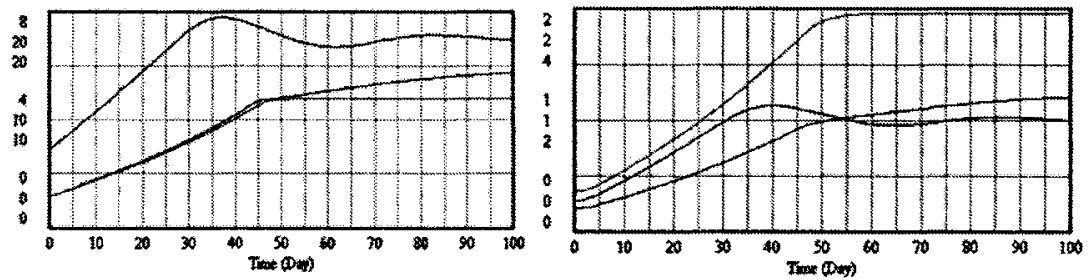

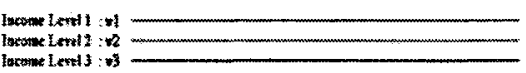

Figure 7. Income Level com

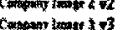
Figure 8. Company Image

Figure. 6 tell we that, in the most intensity context, the CS will be stable in the highest level; from Figure.7, we can read that, the lowest level of intensity will lead to the highest Income level; in Figure.8, we can get the conclusion that, the highest Company Image is generated in the medium level of competition intensity context. So we can conclude that, there exists contrary between CS and Company Image and Income Level. The best context for the company is medium or lowest competition level context, but in this context, the CS is not the highest. So, through analyzing of this simple research, we get the conclusion that improving the CS blindingly can not achieve the real purpose of company (highest income and company image).

\section{LIMITATIONS AND FUTURE RESEARCH}

Limitation of this example is visible: firstly, the result of SEM model is not ideal, this may be due to bad design of questionnaire and lack of samples; secondly, some functions in the model were established without theoretical supports, so the stimulation result is suspicious. For future, we will improve this research in these two directions.

\section{REFERENCES}

1. F.W.E. Reichheld and Z. Sasser, Defections: Quality Comes to Services, Harvard Business Review. Volume 68, pp.105-111, (1990).

2. T.R. Rust and J.A. Zahorik, Customer Satisfaction, Customer Retention, and Market Share, Journal of Retailing. Volume 69, pp.193-215, (1993).

3. W.E. Anderson and T.R. Rust, Customer Satisfaction, Productivity, and Profitability: Differences between Goods and Services, Marketing Science. Volume 16, Number 2, pp.129-145, (1997).

4. M.D. Szymanski and H.D. Henard, Customer Satisfaction: A Meta-Analysis of the Empirical Evidence, Journat of the Academy of Marketing Science. Volume 29, Number 1, pp.16-35, (2001).

5. W.E. Anderson and W.M. Sullivan, The Antecedents and Consequences of Customer Satisfaction for Firms, Marketing Science. Volume 12, pp.125-43, (1993). 
6. T.A. Mooradian and O.M. James, 'I Can't Get No Satisfaction': The Impact of Personality and Emotion on Postpurchase Processes, Psychology \& Marketing. Volume 14, Number 4, pp.379-793, (1997).

7. F.D. Davis, Perceived usefulness, perceived ease of use, and user acceptance of information technologies, MIS Quarterly. Volume 13, Number 3, pp.319-340, (1989).

8. M. Fishbein and I. Ajzen, Belief, Attitude, Intention and Behavior: An Introduction to Theory and Research (Addison-Wesley: Reading, MA, 1975). 